\title{
KONSERVASI BANGUNAN TRADISIONAL DI JEPANG
}

Oleh :

Ir. Suzanna Ratih Sari, MM, MA

Dosen Fakultas Teknik Universitas Diponegoro

\begin{abstract}
Konservasi bangunan tradisional merupakan salab satu upaya yang digunakan untuk melestarikan nilai-nilai budaya yang saat ini cenderung memudar: Banyak generasi muda yang tidak mengenal nilai-nilai budaya yang ada di daerabnya babkan di Indonesia pada umumnya, karena kesadaran masyarakat untuk mengkonservasi bangunan-bangunan yang ada disekitarnya sudab menurun dan babkan cenderung dekonstruktif.

Ada beberapa pengalaman yang dapat dijadikan sebagai baban untuk memabami bagaimana orang-orang di Negara seberang berusaba untuk melestarikan nilai-nilai tradisional yang ada tanpa mengurangi performance bangunan itu sendiri. Pengalaman ini dapat dijadikan sebagai acuan bagi kita masyarakat yang peduli terbadap konservasi untuk mencoba menjaga nilai-nilai budaya yang ada sebingga anak cucu kita dapat menikmati nila-nilai tersebut.
\end{abstract}

Kata kunci : Konservasi, Rumah

Tradisional, Rumah Tradisional Jepang

\section{Pendahuluan}

Mendengar kata konservasi lazimnua kita lantas tertuju pada konservasi alam, dalam arti melestarikan lahan pertanian, melindungi kawasan hutan atau menjaga badan air (danau, telaga, sungai, waduk). Padahal sesungguhnva di sisi lain ada pula konscrvasi terhadap warisan budaya dalam bentuk bangunan kuno dan lingkungan, artcfak-artcfak, atau bahkan kota yang berwawasan identitas.

Tentang konservasi bangunan lama atau tradisional sudah sering dibicarakan, akan tetapi bukan hanya penghancuran terhadap pernak-pernili budaya masa silam saja tetapi cksploitasi terhadap alampun scmakin meningkat. Memang kita tidak bolch aprori terhadap kecenderungan technologeal culture bane melanda berbagat dacrah, baik dalam wujud mixed used development, pembangunan kota, dll. Damun demikian semua lang terkait dengan pembangunan terutama di kawasan-kawasan lang memiliki nilat historis cukup ringer haruslah derencanakan dan drancingedengan mengacu pada konsep-konsep konservasi.

\section{Pengertian Konservasi}

Konservasi adalah semua proses untuk memelihara suatu tempat dan bangunannya guna mempertahankan signifikansi budayanya. (Hermawati, 2004). Proses ini mencakup kegiatan Rehabilitasi, Preservasi, Restorasi/ Rekonstruksi, Revitalisasi/Adaptasi, Demolis, dan Renovasi.

Menurut Piagam Burra (1981), yang dimaksud dengan konservasi adalah scgenap pengelolaan suatu tempat agar makna kultural yang dikandungnya terpelihara dengan baik. Konservasi dapat meliputi seluruh kegiatan pemeliharaan dan sesuai dengan situasi dan kondisi setempat. Dalam suatu lingkungan kota, objek dan lingkup konservasi digolongkan menjadi: 1) satuan areal, 2) satuan pandangan/visual/landscape, dan 3) satuan fisik (bangunan); sedangkan secara umum bentuk konservasi meliputi kota, dcsa, distrik, lingkungan perumahan, bangunan, dan lain-lain.

Mengkonservasi kawasan tidak cukup hanya bangunan fisik saja, tetapi adalah tempatnya (place) juga. Yang dimaksud suatu kawasan konservasi adalah lingkungan fisik beserta isi dan se ielilingnya. Jelas disini bahwa manusia (warga atau siapapun) yang melakukan kegiatan di dalam kawasan harus disandang sebagai suatu kesatuan. Pengembangan wisata berbasis konservasi merupakan kegiatan yang melibatkan kekutsertaan masyarakat sebagai subjek dalam pengelolaan kegiatan pariwisata. Mengembangkan wisata berarti pula menghidupkan kembali nilai-nilai luhur budara asli masyarakat yang penuh kesederhanaan dan nilai tradisional khususnva untuk kepentingan pariwisata. Nilai-nilai original dari massarakat termasuk rumah-rumah tradisional yang mampu bertahan meskipun ada banyak pergaruh vang mencmpansa namun demikian sampai sat ini keberadaan mereka masih tetap cksis. Walaupun selienarnsa ada pengaruh timbal balik antara setting penataan ruang kawasan derean perilaku manusia. Dengan demikian akan berpengaruh pula terhadap bagamana manusta tersebut pada akhirnsa memberikin penghargan terhadap pola tata ruang yang ada. Permasalahan saat ini adalah banyak sekali masyarakat yang tidak menyadari akan nilai-nilai konservasi terhadap kondisi yang ada, bahkan seiring dengan perkembangan jaman banyak sekali peninggalan. peninggalan lama dan bersejarah serta memiliki nilai tambah yang cukup tinggi dibiarkan rusak untuk selanjutnya dibongkat menjadi bangunan baru atau modern. Kondisi demikian memang sangatlah memprihatinkan, sehingga perlu cara atau strategi yang harus segera dilakukan oleh pemerintah khususnya dalam mengantisipasi punahnya bangunan-bangunan lama tersebut termasuk rumah-rumah tradisional. Karena bagaimanapun, kita punya banyak sekali ragam budaya yang memberikan warna terhadap rumah-rumah tradisional, sehingga kalau tidak diperhatikan akan segera hilang dan bahkan punah.

\section{Pengertian Rumah Tradisional}

Rumah tradisional sebagai perwujudan dari hasil kebudayaan masyarakat bermula dari karya Folk Architecture yang merupakan arsitektur alami yang menjadi dan berproses pada suatu masyarakat dari wilayah tertentu. Kemudian berkembang menjadi arsitektur vernakular yang telah dimodifikasi dengan unsur budaya. iklim dan bahan (Wiranto, 1997) yang memungkinkan manusia hidup berdampingan dengan alam serta untuk melihat manusia dan arsitektur sebagai bagian dari ekosistem dunia (Hasegawa dan Margurie, 1976 dalam Jencks, 1997). Jadi manusia lahir untuk hidup dalam hubungan saling ketergantungan dengan alam. Terdapat nilai-nilai tradisional yang terpendam dalam sebuah bangunan arsitektur vernakular vaitu (Jencks, 1997):

1) Vernakular menunjukkan bagaimana bersikap jujur. Sebagai contoh, bagaiman memadukan materialmaterial vang ssuai untuk membentuk kesatuan struktur yang koheren vang berhubungan dengan keseimbangan ckonomisebagai komunitas makhluk hidup.

2) Vernakular memperlihatkan karakter rang kompleks sebagai karra arsitektural vang lahir dari kejujuran tersebut, ang dibuat secara sederhana dalam kompleksitas ans 
nyata.

3) Vernakular memiliki kualitas yang sulit dipahami yaitu skala manusia yang merupakan pelajaran membangun yang langsung dari masyarakat untuk masyarakat .

Rumah tinggal pada masyarakat tradisional merupakan media yang paling memungkinkan untuk mengekspresikan sistem religi, dan nilai/norma yang dimiliki (Frick dalam Gunawan, 1999). Di dalam arsitektur rumah tradisional terkandung secara terpadu wujud-wujud riil, sosial dan materiil suatu kebudayaan.

Bila ditarik kesimpulan, maka rumah tradisional merupakan cerminan budaya dan kecenderungan sifat kebudayaan yang terbentuk karena tradisi dan kondisi iklim setempat yang tidak mudah berubah.

\section{Konservasi Rumah-rumah Tradisional Jepang}

Guna memahami perbedaan budaya, sekiranya penting bagi kita untuk mengetahui secara sekilas tentang design rumah dari berbagai Negara seperti Jepang. Jepang sebagai Negara maju sangat concern terhadap bangunan-bangunan tradisional. Beberapa peraturan dibuat untuk melindungi eksistensi bangunanbangunan tradisional disana. Sepertiyang telah diketahui bersama bahwa pada umumnya rumah-rumah tradisional Jepang memiliki pola tata ruang yang cukup unik dibandinkan rumah-rumah tradisional Jawa. Perbedaan budaya telah memberikan warna ataupun onsep pembangunan perumahan yang berbeda. Di Jepang sampai saat ini masih sangat mudah untuk mendapatkan beberapa rumah tradisional, bahkan kampongkampung tradisional. Beberapa policy yang mendukung eksistensi rumah-rumah tersebut cukup kuat dan dilaksanakan oleh masyarakat. Tidak demikian halnya dengan masyarakat kita di Indonesia. Masyarakat Indonesia cenderung ingin mengikuti pola, gaya, kebutuhan saat ini. Bahkan banyak sekali bangunan-bangunan tradisional yang ada di demolish dan diganti dengan performance yang baru yang lebih modern.

Di Jepang, bahkan dalam perencanaan rumah tinggal yang modern saat ini masih menerapkan konsep-konsep tradisional seperti ukuran tatami floor mat ala jepang) yang disebut sebagai jo. Ada beberapa jenis ukuran, misalnya $4.5 j o$, (ojo, 910, $11 \%$.

Apabila kita melihat pola tata

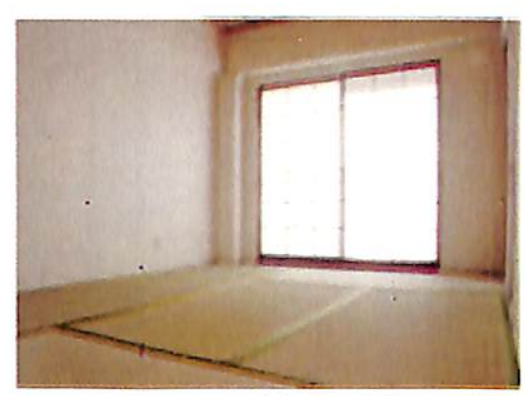

Ruang tatami dengan shoji

ruang dalam rumah tradisional Jepang dapat disebutkan disini bahwa interior rumah Jepang terdiri dari entrance area (genkan), ruang tidur, dapur, kamar mandi, untuk rumah yang sederhana, sedangkan rumah tradisional Jepang yang lebih besar biasanya memiliki, ruang keluarga sekaligus sebagai ruang makan, ruang tamu dan bahkan beberapa diantaranya ruang toko.

Keunikan dari design rumah tradisional Jepang ini adalah bagaimana mereka mendesign ruang secara efektif dan efisien namun tetap sesuai dengan fungsi yang diharapkan. Kebanyakan orang-orang Jepang menggunakan furniture yang portable sehingga mudah untuk dipindahkan, digeser atau bahkan disimpan. Sehingga meskipun rumah mereka kecil namun mereka tetap memiliki ruang-ruang yang mereka inginkan seperti : ruang tamu yang biasanya juga dijadikan sebagai ruang tidur dan bahkan ruang keluarga. Hal ini memungkinkan karena masyarakat Jepang mendesain ruang tamu sedemikian rupa sehingga memungkinkan kita untuk dengan mudah mengganti fungsi ruang dengan didukung penggunaan furniture yang simple sehingga mudah dalam melakukan penyimpanan. Tempat tidur misalnya, mereka banyak menggunakan futon dan tidak menggunakan rangka tempat tidur sehingga selesai digunakan dapat segera disimpan di gudang kecil (oshiire)yang selalu ada di ruang tamu ini (ima).

Bahkan mereka sudah menyiapkan lantai ruangan dengan tikar (tatami) diatasnya sekaligus sebagai alas yang digunakan untuk tidur. Konsep tatami inilah yang sapai saat ini masih ada dan eksis di dalam perencanaan rumah tradisional bahkan rumah-rumah modern. Rumah-rumah tradisional Jepang seringkali menggunakan partisi yang terbuat dari kayu dan kertas (fusuma) yang dapat dengan mudah dibongkar dan sifatnya portable. Sehingga dapat digunakan untuk membuat ruang di dalam rumah. Demikian juga dengan shouji yakni slidding door yang juga terbuat dari kavu dan kertas dan bersifat transparan sehingga

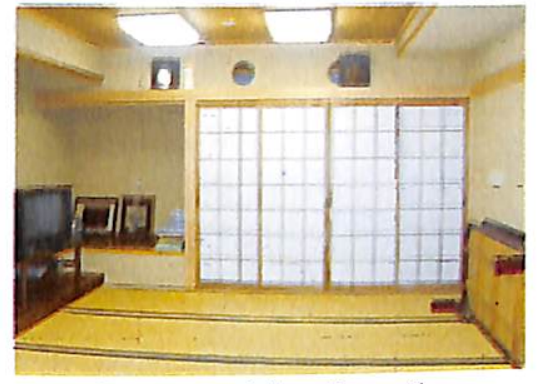

Ruang tamu sckalligus Ruang tidur

orang lewat masih bisa terlihat.

Dari pola interior rumah tradisional diatas sampai saat ini kita masih dengan mudah mendapatkan pola-pola penataan ruang seperti yang sudah dipaparkan diatas. pada rumah-rumah Jepang saat ini. Disini kita bisa melihat betapa kuatnya mereka mempertahankan nilai-nilai budaya yang mereka miliki. Bahkan di Jepang mereka juga memiliki museum yang didalamnya tidak sekedar menampilkan miniature rumah tradisional Jepang berikut dengan kehidupannya melainkan juga rumah-rumah dalam bentuk dan ukuran asli rumah tradisional sehingga pengunjung dapat betul-betul menikmati suasana pada waktu itu dari pagi hari hingga malam hari. Museum ini sangat menarik karena pengunjung dapat memahami bagaimana kehidupan masyarakat Jepang pada jaman dulu karena pada museum ini menampilkan satu sisi kehidupan di satu koridor jalan. Sehingga tidak hanya rumah tradisional sebagai satu unit yang bisa dilihat tetapi rumah tradisional lengkap dengan lingkungan dan pola kehidupan yang terjadi. Museum ini salah satunya terletak di Kyoto. Rumah tradisional yang ditampilkan adalah rumah -rumah tradisional dari berbagai golongan ekonomi baik masyarakat berpenghasilan rendah, menengah sampai atas. Dari kondisi ini kita bisa melihat berbagai macam perbedaan yang cukup signifikan antara rumah tradisional masyarakat bawah yang begitu kecil dan sederhana sampai rumah toko yang biasa digunakan sebagai indikasi rumah masyarakat bagi orang yang mampu.

Secara garis besar, sebenarnya bentuk-bentuk rumah Jawa lebih bervariatif dan lebih menarik untuk dipelajari, karena rumah Jawa dapat dibedakan menjadi empat macam, yaitu rumah bentuk joglo, bentuk limasan, bentuk kampung, dan bentuk panggangpe. Rumah bentuk joglo pada kenvataannya hanva dimiliki oleh orangorang yang mampu, karena untuk membangun rumah ini dibutuhkan bahan bangunan yang lebih banyak dan tentunya akan lebih mahal. Susunan ruangan dibagi menjaditiga 


\section{Tematik}

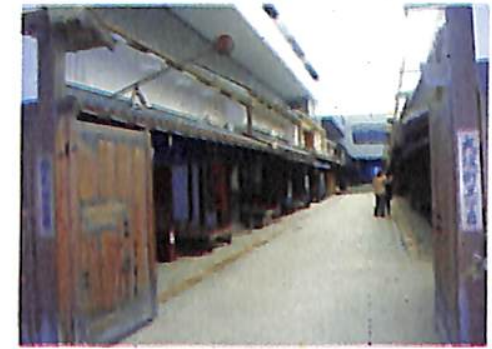

Perkampungan tradisional Kyoto yang terdapat di museum Perumahan di Kyoto Jepang

bagian, yaitu bagian depan sebagai ruang pertemuan disebut pendhapa, ruang tengah untuk tontonan wayang kulit disebut pringgitan, serta ruang belakang sebagai ruang keluarga disebut dalem. Bahkan di konsep rumah Jawapun memiliki konsep "kawruh kalang" dalam membangun rumah. Nilai-nilai inipun saat ini sudah banyak dilupakan oleh masyarakat Jawa.

Contoh lain dari kebijakan pemerintah Jepang yang dapat kita pelajari yakni bagaimana mereka mempertahankan perkampungan tradisional melalui beberapa policy yang diterapkan. Kondisi ini dapat dilihat perkampungan di salah satu tempat tujuan wisata di Nagoya yakni Magome dan Tsumago. Magome merupakan permukiman tradisional yang masing-masing rumah memiliki konsep pembangunan yang berbeda satu dengan yang lain sehingga memberikan warna pada performance dari masing-masing bangunan.

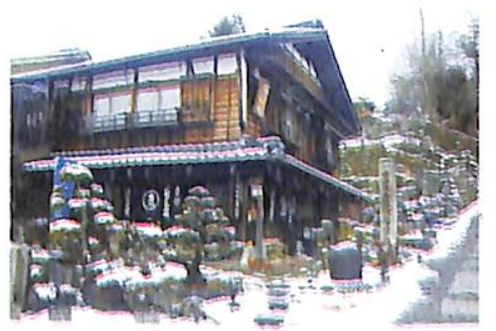

Salah Satu Bentuk Rumah Tradisional di Magome

Pola permukiman di Magome ini dari dulu hingga sekarang masih tetap sama sehingga menarik untuk dikunjungi wisatawan.

Lain halnya dengan Tsumago, di daerah ini juga merupakan permukiman tradisional yang masih utuh dan asli. Uniknya di daerah ini ada peraturan pemerintah yang meminta masyarakat untuk tidak menjual rumah mereka, merenovasinya atau bahkan memusnahkan. Masyarakat di Tsumago ini diminta untuk mempertahankan rumah asli mereka dan mempertahankan nilainilai budaya vang ada hingga saat ini. Rumah-rumah kavu yang sangat sederhana dengan konstruksi rumah yang khas karena menggunakan kayu-kayu ukuran besar untuk konstruksi atapnya dan penggunaan material local sebagai bahan pembangunan rumah tradisional dan bentuk-bentuk rumąh khas Jepang bisa ditemui di daèrah ini. Baik Magome maupun Tsumago di pakai sebagai salah satu atraksi wisata yang dapat dinikmati dari seluruh lapisan masyarakat baik anakanak, muda maupun tua. Sungguh sangat mengagumkan, karena kecenderungan masyarakat modern lebih memilih untuk mendesain rumahnya dengan bentukbentuk dan teknologi modern, tetapai masyarakat di Magome dan Tsumago masih tetap eksis dan bahkan mempertahankan tradisi dan rumahrumah tradisional mereka.

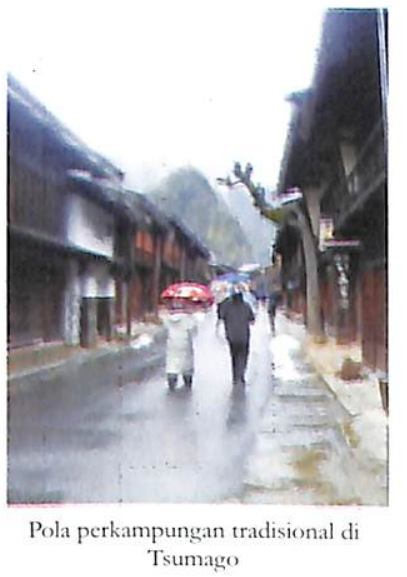

Kesimpulan

Dari paparan diatas kita dapat melihat bagaimana masyarakat Jepang masih sangat menghargai nilai-nilai budaya yang mereka miliki sehingga untuk mengantisipasi pudarnya nilai-nilai budaya tersebut mereka berusaha untuk membuat replica secara utuh dan disesuaikan dengan kondisi yang ada pada saat itu sehingga bermanfaat bagi anak-anak untuk dapat melihat, mempelajari bahkan dan memahami kehidupan masyarakat pada jaman itu.

Perlu adanya peraturan yang jelas dalam usaha untuk melestarikan keberadaan bangunan-bangunan tradisional dan perlu kesadaran dari masyarakat untuk dapat mempertahankan nilai-nilai budaya yang kita punya sehingga baik peraturan pemerintah maupun masyarakat dapat saling mendukung. Implementasi nyata dari masyarakat dan penentu kebijakan tentunya juga menjadi factor yang utama dalam melestarikan nilai-nilai tradisional tersebut. $\bowtie$

\section{Referensi}

Jenks, Charles, Theories and Manifestos of Contemporary Architecture, Academy Addition, 1997, Great Britain

Rapoport, A, 1969, House Form and Culture, Prentice Hall, Inc. Englewood Cliff, N.J New York, Pargamon Press

The Burra Charter for the Conservation of Place of Cultural Significance, 1981

Tjahyono, Gunawan, 1989, Dissertasi, Cosmos, Centre and Duality in Javanese Architectural Traditional : The Symbolic Dimentions of House Shapes in Kota Gede and Surroundings, University of California, Berkeley

Wiranto, 1997, Cakrawala Arsitektur, Badan Penerbit Universitas Diponegoro, Semarang

Wiranto, Pelangi Arsitektur, Badan Penerbit Universitas Diponegoro, 1997, Semarang

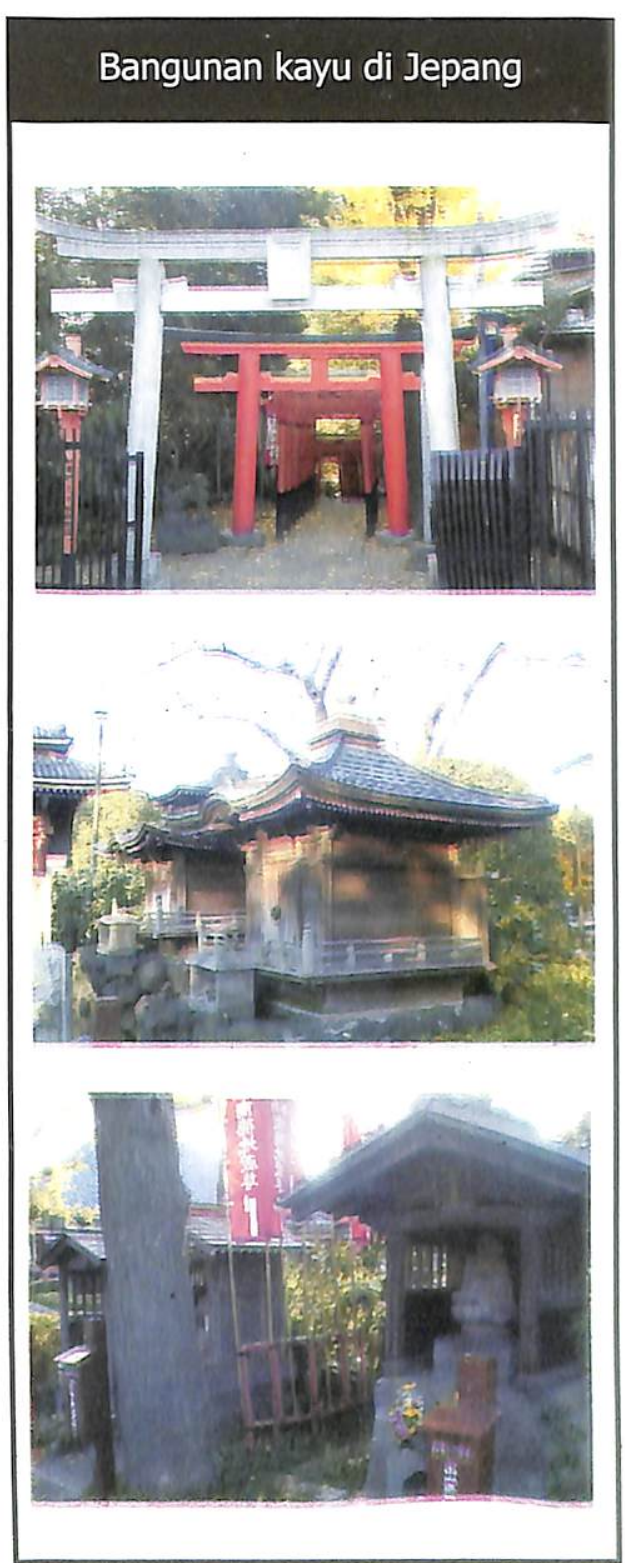

